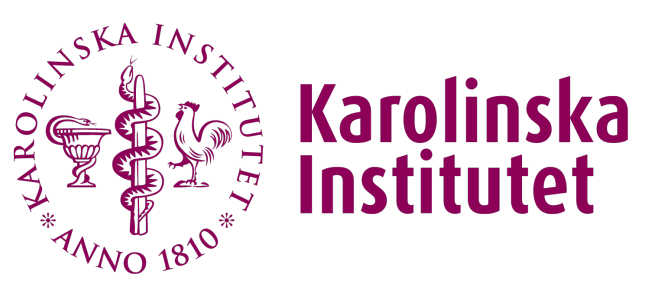

Karolinska Institutet

http://openarchive.ki.se

This is a Peer Reviewed Accepted version of the following article, accepted for publication in International Psychogeriatrics.

2016-01-18

\title{
Individual variability and environmental characteristics influence older adults' abilities to manage everyday technology
}

Malinowsky, Camilla; Almkvist, Ove; Nygård, Louise; Kottorp, Anders

Int Psychogeriatr. 2012 Mar;24(3):484-95.

http://doi.org/10.1017/S1041610211002092

http://hdl.handle.net/10616/44996

If not otherwise stated by the Publisher's Terms and conditions, the manuscript is deposited under the terms of the Creative Commons Attribution-NonCommercial-NoDerivatives License (http://creativecommons.org/licenses/by-nc-nd/4.0/), which permits non-commercial re-use, distribution, and reproduction in any medium, provided the original work is properly cited, and is not altered, transformed, or built upon in any way. 


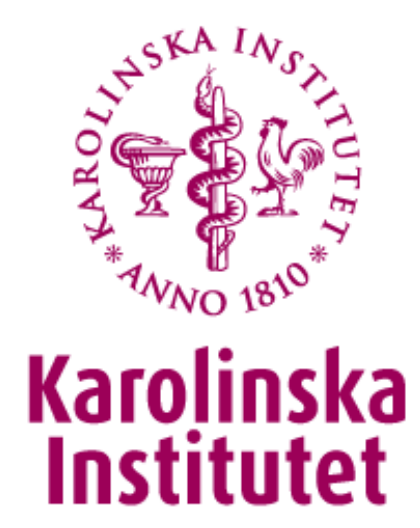

This is an author produced version of a paper published in International Psychogeriatrics. This paper has been peerreviewed but does not include the final publisher proofcorrections or journal pagination.

Individual variability and environmental characteristics influence older adults' abilities to manage everyday technology. 2012 Mar;24(3):484-95.

Malinowsky, Camilla; Almkvist, Ove; Nygård, Louise; Kottorp, Anders

\section{URL: $10.1017 /$ S1041610211002092}

Access to the published version may require subscription. Published with permission from: Cambridge University Press 
Individual variability and environmental characteristics influence older adults' abilities to manage everyday technology.

\section{Abstract}

Background: The ability to manage everyday technology (ET) such as computers and microwave ovens is increasingly required in the performance of everyday activities and participation in society. This study aimed to identify aspects that influence the ability to manage ET among older adults with and without cognitive impairment. Methods: Older adults with mild Alzheimer's disease and mild cognitive impairment and without known cognitive impairment were assessed as they managed their ET at home. Data was collected with the Management of Everyday Technology Assessment (META). Rasch-based measures of the person's ability to manage ET were analyzed. These measures were used as dependent variables in backward procedure ANOVA analyses. Different pre-defined aspects that could influence the ability to manage ET were used as independent variables. Results: Three aspects had a significant effect upon the ability to manage ET. These were: (1) variability in intrapersonal capacities (such as "the capacity to pay attention and focus", (2) environmental characteristics (such as "the impact of the design") and (3) diagnostic group. Conclusions: Variability in intrapersonal capacities seems to be of more importance than the actual level of intrapersonal capacity in relation to the ability to manage ET for this sample. This implies that investigations of ability to manage ET should also include intra-person variability. Additionally, adaptations in environmental characteristics could simplify the management of ET to support older adults as technology users.

Key words: Alzheimer's disease, mild cognitive impairment, ADL, IADL. 


\section{Running title: Aspects influencing use of everyday technology}

\section{Introduction}

At present, an increasing amount of everyday activities, such as handling remote controls, radios, and automatic telephone services require the use of ET. Due to the augmented use and variety of technology in society, the performance of everyday activities has changed and often become more technologically complex, for example we use Internet banking instead of visiting a bank office (Emiliani, 2006). Ability to manage the technology can therefore be seen as a part of both performance of everyday activities and participation in society (Czaja et al., 2006; Slegers et al., 2007). Recent studies have shown that people with mild Alzheimer's disease $(\mathrm{AD})$ and mild cognitive impairment (MCI) perceive ET as less relevant than do older adults without known cognitive impairment (Rosenberg et al., 2009). Samples with AD and MCI have also demonstrated a decreased ability to use ET when compared to controls (Malinowsky et al., 2010; Rosenberg et al., 2009), although overlaps were large. Accordingly, it is not possible to predict a specific person's ability to manage ET based only on presence or absence of an AD or MCI diagnosis. This indicates that identification of other aspects influencing older adults' ability to manage ET (such as gender, familiarity with the ET, motivation) is also required. Further knowledge of such aspects might simplify health care professionals' decisions on the design of interventions to support everyday activities where management of ET is included. Finally, as current research has indicated that persons with cognitive impairments may demonstrate considerable fluctuations in their cognitive capacities (Holtzer et al., 2008; Lövdén et al., 2007), it may be crucial not only to identify which aspects influence the ability to manage ET, but also if and how potential variations in these aspects may be influential. Hence, this study aims to identify aspects that influence the abilities of older adults with and without cognitive impairment to manage ET. 
The management of ET includes not only the observable ability to manage the technology but also other aspects that might have influence, such as design and familiarity with the technology. In earlier studies, factors that predict use and non-use of ET have been studied, including sociodemographic factors, users' attitudes and cognitive capacities (Selwyn et al., 2003; Czaja et al., 2006), but there is still a lack of studies of aspects that are likely to influence how users with and without dementia actually manage to use the ET (Nygård and Starkhammar, 2007).

Previous research has examined the relationship between the ability to manage everyday activities in general and potentially influential aspects in a variety of populations, including older adults with and without cognitive impairment. In numerous studies, decreased cognitive capacities (as measured by assessment of cognitive capacities) have been found to have a negative association with function in everyday activities (Van Hooren et al., 2005; Pereira et al., 2008). The results from 68 studies examined in a review by Royall et al. (2007) showed that cognitive measures on average explain $21 \%$ (median 16\%) of the variance in outcome of function in everyday activities. Studies that have specifically studied older adults with dementia or MCI show the same pattern, a positive relationship between decline in cognitive capacities and lower ADL and IADL (Perneczky et al., 2006; Farias et al., 2006). However, these studies also show that cognitive capacity only partly explains the variance in the function of everyday activities. Additionally, intra-person variability in cognitive capacity has been suggested as a predictor for cognitive decline (Holtzer et. al., 2008; Lövdén et al., 2007). This indicates that it is not enough to assess only the status of cognitive capacity in order to get information about the ability to manage everyday activities. 
Moreover, the ability to manage everyday activities is also influenced by the physical and social environment, as the environment may be a hindrance as well as a facilitator (Kielhofner, 2008). The supportive features of the environment are of particular importance for persons with dementia as they are not expected to increase their capacity to meet the environmental constraints (Giovannetti et al., 2007). The design of the physical environment is also regarded as a therapeutic resource to promote functionality in persons with dementia (Day et al., 2000).

To summarize, it is known that a variety of aspects can affect the ability to manage everyday activities in general. But more knowledge is needed in order to understand if the ability to manage ET is affected in a similar manner. No studies have actually evaluated the associations between different aspects influencing everyday functioning and the actual performance skills when older adults with or without cognitive impairment use ET (i.e. not only use vs. non-use). Finally, most studies evaluating aspects influencing everyday functioning in older adults with and without cognitive impairment have evaluated these aspects as static, not taking into consideration potential variations in person-related or environmental characteristics. In order to make decisions on how best to support older adults with and without cognitive impairments experiencing difficulties in the management of ET, knowledge of aspects that affect the ability as well as knowledge of how these aspects interact with each other is necessary. The aim of this study, therefore, was to identify aspects that influence the ability to manage ET among older adults with and without cognitive impairment. 
Methods

\section{Participants}

This study is based on assessments of 110 older adults living at home. The sample comprised people with mild AD ( $\mathrm{n}=35)$, people with $\mathrm{MCI}(\mathrm{n}=33)$, and older adults without known cognitive impairment $(\mathrm{OA})(\mathrm{n}=42)$ (see Table 1). In the analyses the sample was treated as one group of older adults with and without cognitive impairment. Participants with AD or MCI were recruited from memory clinics and day care centers for people with dementia in two urban areas in Sweden, and the OA sample was recruited through voluntary retirement organizations. Of the 173 invited, 63 persons, some people with $\mathrm{AD}(\mathrm{n}=27)$, MCI $(\mathrm{n}=25)$ and OA $(\mathrm{n}=11)$ declined to participate in the study. The declines had several explanations. Thirty-four persons were not interested in participating, ten persons declined to participate due to time constraints, sixteen persons were not able to participate due to health-related or personal reasons and finally three persons could not be reached. Additionally, four participants were excluded from the analyses due to missing data.

The age inclusion criterion for all participants was that they were to be 55 years or older. The participants were also to use common ET in everyday life. Furthermore, people with visual and/or hearing impairments were included as long as their impairment(s) could be compensated with appropriate devices so the assessment could be carried out. In addition, Mini-Mental State Evaluation (MMSE) (Folstein et al., 1975) scores, measured no more than six month earlier, of a minimum $18 / 30$ for people with mild AD, 25/30 for people with MCI and 27/30 for older adults without cognitive impairment were used as inclusion criteria. Participants with AD were diagnosed by physicians based on NINCDS-ADRDA (McKhann et al., 1984) and DSM-IV (American Psychiatric Association, 1995). The participants with MCI were diagnosed by physicians basing their decisions on the diagnostic criteria for MCI 
(Petersen, 2004; Winblad et al., 2004). The OA were included to be matched on a group level to their counterparts with $\mathrm{AD}$ or MCI regarding gender, age, and years of education. Before the study was initiated, an approval from the local Ethical Committee was obtained (Journal no. $2005 / 1203-31)$.

\section{[Insert Table 1 about here]}

Data Source

The Management of Everyday Technology (META)

The Management of Everyday Technology Assessment (META) was used to assess the participants' ability to manage their own self-chosen ET. The META was developed to assess the ability to manage ET in everyday activities for older adults in general and specifically for people with mild dementia or MCI (Malinowsky et al., 2011; Nygård and Starkhammar, 2007). The META is divided into three different constructs for evaluation: the person's observed performance skills when using ET ( $n=10$ items. See Table 2$)$, the intrapersonal capacities $(n=3$ items: the capacity to manage stress, the capacity to pay attention and focus, and the capacity to recall necessary information), and environmental characteristics ( $\mathrm{n}=2$ items: the contextual influence and the impact of the design). The META also includes questions concerning the familiarity with the ET assessed ( $n=2$ items: how long and how often the ET has been used). For detailed information of the items in the META, see Table 2. In the ten performance skill items, observable performance skills that have been found essential to the ability to manage ET are assessed. These include identify and separate objects, coordinate different parts of a technology, and manage a series of numbers (Malinowsky et al., 2011; Nygård and Starkhammar, 2007). All items are evaluated by a rater in relation to the use of each specific ET chosen in each case. In addition, data from the remaining two constructs provides information about other aspects involved in the management of ET. Their impact on the ability to manage the specific ET is assessed by the rater. 
The psychometric properties of the ten performance skill items in the META have been evaluated elsewhere (Malinowsky et al., 2011), and they were found to demonstrate acceptable rating scale validity and acceptable person response validity ( $97.5 \%$ goodness-of-fit). The META was also found to be able to separate individuals with higher ability from individuals with lower ability on a group level (Malinowsky et al., 2011). However, the META was not developed for diagnostic purposes nor used for diagnostics of AD or MCI in this specific study.

\section{[Insert Table 2 about here]}

\section{Procedures}

Seven trained raters collected data. All raters were occupational therapists with experience in working clinically with people with dementia. Before the data collection was initiated, all raters participated in a one-day course covering general information about the assessment instrument to be used. It included the META and its definitions, procedures, and scoring criteria in order to maximize the accuracy of scoring. During the one-day course the raters practiced scoring by assessing an older adult's videotaped use of four ETs. In an evaluation of the psychometric properties of the META, acceptable consistency (intra-rater reliability) within raters was indicated (Malinowsky et al., 2011). All raters demonstrated acceptable goodness of fit to the Rasch measurement model with outfit $\mathrm{MnSq}$ between 0.65 and 1.25. During the data collection process, raters continuously discussed unclear issues using the META assessments in personal communication with each other and the creator of the META (the third author, LN).

Data collection was performed in the participants' homes or nearby, depending on the kind of ET to be assessed. Additionally, during the data collection, descriptive data was gathered on age, gender, living conditions, years of education, and former occupation, and for the OA group 
also the MMSE. The participants were observed in one session in their homes while using their own, relevant, self-chosen, and currently used ET. The ET was also chosen on the basis of being sufficiently challenging for each participant. The level of challenge of the ET was based on the hierarchy of ET difficulty that had been created on the Everyday Technology Use Questionnaire (Rosenberg et al., 2009). After an opening dialogue, the participant was asked to demonstrate the use of a few of his/her own ETs that were relevant but somewhat challenging. The participant's performance was thereafter observed and assessed by the rater on the ten performance skill items in the META using a three-category scale. Categories were: $3=$ no difficulty, 2=minor difficulty, and 1=major difficulty. Additionally, the impact on the ability to manage ET based on the remaining five items was assessed and scored by the rater using the same three-category scale. And finally, data concerning the two familiarity items, how long and how often the ET was used, was collected by the same rater for each of the ETs evaluated. The answers of the two familiarity items were divided into five categories for each item (see Table 3). The raters' scores were based on the scoring criteria in a META manual (unpublished research version of manual, Nygård).

Preparatory data analysis

Based on the assessment of the 10 performance skill items in the META, a computer application of the FACETS Rasch rating scale model, version 3.61.0 (Linacre, 1987-2006) was used to estimate the ability measure of the actual performance in the management of ET for each participant. The Rasch measurement model converts raw score data through logistic transformation into abstract interval units called log-odds probability units, logits (Bond and Fox, 2007). From the FACETS analyses, all participants received an ability measure presented in logits. These person ability measures of the ability to manage ET were used as the dependent variable in the analysis. 
Selection and definition of independent variables

The potential effect on the measures of ability to manage ET (the dependent variable) was thereafter evaluated for a number of aspects (independent variables) using a general linear model (GLM) analysis of variance (ANOVA). With ANOVA analyses it is possible to use categorical as well as metric data. Three descriptive aspects, (1) diagnostic group, (2) gender (earlier shown to have a significant effect on the ability to manage ET (Malinowsky et al., 2010)), and (3) occupation, were selected for analysis. Two constructs from the META assessment (intrapersonal capacities and environmental characteristics) and the familiarity with the ET were also selected for analysis. The variables of intrapersonal capacities, environmental characteristics, and familiarity are based on the classification of the items in the META (for further description of the independent variables, see Table 3).

All participants were assessed on a minimum of two different ETs; each participant had at least two assessments (range 2-7, mean 3.15, SD 1.05) on each of the skill items. In order to make the analysis of the data from the three META constructs feasible, they were put into two different categories. First, the central tendency (low or high median in the scores for all ETs assessed in each participant) was calculated for each construct, respectively (see Table 3). Second, the variation (four classes of variation within the scores for all ETs assessed in each participant) was calculated for each construct, respectively. (Examples of these estimations are shown in Table 4). After these categorizations, each participant had six independent variables based on the META for further analysis. They included: (1) intrapersonal capacities: central tendency and (2) variation, (3) environmental characteristics central tendency and (4) variation, and (5) familiarity central tendency and (6) variation.

[Insert Table 3 about here] 


\section{[Insert Table 4 about here]}

Primary data analysis

The next step in the data analysis was to conduct ANOVA analyses in order to guide the choice of aspects to be included in the final model. For evaluation of the data, the Statistical Package for Social Sciences was applied (2007). The independent variables tested in the analyses were the following. From the demographic data came: (a) diagnostic group, (b) gender, (c) occupation. From the data generated from the META assessments came: (d) intrapersonal capacities central tendency, (e) variation, (f) environmental factors central tendency, (g) variation, (h) familiarity with the ET central tendency, and (i) variation. All variables were treated as categorical variables. In the analyses, the total sample of 110 older adults with and without cognitive impairment was analyzed together as one group. A backward selection procedure was conducted to reduce statistically redundant variables (those not significantly [ $p$-value less than 0.05 ] associated with the dependent variable, i.e. the META measure of person ability) in the final model of the ANOVA analysis. Independent variables that were not significantly associated with the dependent variable were removed. However, the earlier defined variables (Malinowsky et al., 2010) of diagnostic group and gender were included in the final model regardless of $p$-value. The backward selection procedure was chosen due to lack of earlier knowledge of the explorative variables.

Bonferroni corrections were performed to minimize the risk for errors arising from multiple comparisons. Normal probability plots were used for visual inspection to ensure that data fulfilled criteria for model assumption. Correlation analyses were also conducted between the independent variables in order to detect potential interaction effects between the independent variables in the analysis. Cook's distance was used to reveal highly influential observations of the model fit. 
Results

The distribution of the META measures of person ability to manage ET followed an approximately normal distribution. The normal probability plots showed that the variables fulfilled criteria for model assumption. In the correlation analyses between the different independent variables, no unexpected notable linear or nonlinear correlations were found, indicating no major threats to the further statistical analyses. In the inspection of Cook's distance no highly influential outliers were detected.

The backward procedure ANOVA analyses indicated three independent variables that had a significant effect upon the dependent variable, i.e. the META measure of person ability to manage ET. These were: (1) the intrapersonal capacities (variation), (2) the environmental characteristics (central tendency), and (3) the diagnostic group. The group-wise frequencies of the different classes of the significant independent META variables are presented in Table 5. The rest of the independent variables (see Table 3) did not have significant effects on the dependent variable. Of these non-significant independent variables, it was decided to include only the earlier defined significant variable, gender, in the final model. Consequently, in the final model of the ANOVA analysis, the following four independent variables were evaluated with the following overall $p$-values: diagnostic group $(p<0.001)$, gender $(p<0.218)$, the intrapersonal capacities variation $(p<0.003)$, and environmental characteristics central tendency $(p<0.001)$. Comparisons between groups and classes of independent variables (using Bonferroni corrections) revealed significant differences between: a) mild $\mathrm{AD}$ and $\mathrm{OA}, \mathrm{b}$ ) no and average/high variation in intrapersonal capacities, and c) low and high central tendency in environmental characteristics. For detailed information see Table 6. The final ANOVA analysis demonstrated an adjusted $\mathrm{R}^{2}$ of 0.517 . Accordingly, the final model explains $51.7 \%$ of the variation of the ability to manage ET. 


\section{[Insert Table 5 about here]}

[Insert Table 6 about here]

\section{Discussion}

This study investigates how a set of predetermined aspects influenced the ability to manage ET among a sample of older adults with and without cognitive impairment. Three aspects were found to be significantly associated with a low ability to manage ET. First, the variation in intrapersonal capacities ("the capacity to manage stress", "the capacity to pay attention and focus", and "the capacity to recall necessary information") was negatively associated with ability to manage ET. Second, the central tendency regarding environmental characteristics, ("the contextual influence" and "the impact of the design") negatively influenced the ability to manage ET. These results show that it is important to take intrapersonal capacities as well as environmental characteristics into account. The importance of the fit between a person's capacities and the environmental demands has been theoretically described by Kielhofner (2008). The results from the present study do not just empirically support these theoretical models. Rather they contribute a more dynamic view of personenvironment fit, as the variability in intrapersonal capacities as well as environmental characteristics significantly contributed to the demonstrated generic skills required to manage ET. The results from this study thus underscore that intrapersonal capacities and environmental characteristics should be considered together, including attention paid to variability. Thirdly, the diagnostic groups were shown to be associated with the META person ability measures to manage ET. This was also demonstrated in an earlier study (Malinowsky et al., 2011). However, in this earlier study all the diagnostic groups differed significantly while in this study only the groups of mild AD and OA differed significantly. The interaction between the independent variables (both person-related and environment-related) in this study 
impacting on the ability to manage ET may need to be further explored in future studies in order to understand the person-environment interaction contextualized in the use of ET. In the earlier study (Malinowsky et al., 2011) the final regression model (including diagnostic group and gender) explained $35.9 \%$, compared to the $51.7 \%$ in the present study, of the ability to manage ET. Accordingly, adding information regarding the variation in intrapersonal capacities and impact of environmental characteristics to a diagnostic evaluation better predict a specific person's ability to manage ET. In the following parts of the discussion, these three influential aspects will be further elaborated upon. The results from this study showed that the most important part of the intrapersonal capacities impacting negatively on the ability to manage ET was the variation in intrapersonal capacities in relation to each assessed ET, rather than the clients' actual capacity status. Even though we found in an earlier study that overall cognitive status , reflected in the level of disease severity (Malinowsky et al., 2011), also impacts on the ability to manage ET, the variability within the person's capacities when observed using a number of ETs is important as well. This suggests that future evaluations of older clients need to take different situations and circumstances into consideration in order to detect potential problems, as we cannot reliably assume that a client's capacities presented in one context or situation are representative for him/ her in other ones. However, in comparisons of classes of variation not all classes differed significantly. Individuals with no variation in intrapersonal capacities differed significantly from individuals with average or high variation, while those with low variation did not differ from others. Maybe just two classes (no-low and average-high) of variation would be enough to detect the influence of the variation. Nevertheless, the results demonstrated a significant influence on ability to manage ET by this explorative aspect. Variability in ability hence ought to receive more attention in clinical investigations, as Lövdén et al. suggest (2007). Additionally, intra-person variability across neuropsychological tests has been demonstrated to be associated with the incidence of 
dementia (Holtzer et al., 2008), and it is possible that variability in ability to manage ET could be a marker of cognitive impairment and dementia. In future studies it would be interesting to investigate the variability in other everyday activities for older adults with and without cognitive impairment. Moreover, gender, which was shown to be associated with the ability to manage ET in an earlier study (Malinowsky et al., 2010), did not fall out as a significant aspect in the present study. The results in the earlier study showed that being a male increased the mean person ability measure to manage ET and it has previously been shown that decreased ability to perform IADL, especially for woman, is a significant risk factor for progression to dementia (Artero et al., 2008). The reason for gender not being a significant variable in this study might be that the variation in intrapersonal capacities has a stronger association to the META person ability measure than gender, and thereby removes gender as a significant variable. This would be interesting to investigate further in future studies.

The results also demonstrated that environmental characteristics could be significant for the ability to manage ET in older adults with and without cognitive impairment. It is not surprising that the level of "contextual influence", when using an ET, and "impact of the design" of an ET were found to be of importance for this management. The impact of environmental conditions on activity performance was known earlier (Kielhofner, 2008). As dementia is a progressive disease and persons with dementia are not expected to increase their cognitive capacities through training, environmental conditions may be of extra importance to consider in retaining their ability to use ET. To manipulate the environmental characteristics in terms of ET design (for instance to limit the number of buttons on a remote control or to make symbols on a microwave oven more clear for the user) might thus be one intervention. If we can adjust the environmental impact to suit the person and the situation, reflected both in the design as well as in the social and physical context where technologies are used, the 
results from this study indicate that such interventions will be beneficial for the overall management of ET by older adults. The use of the META can support clinicians not only with information about which ETs are crucial to focus on in intervention, and about resources and limitations in the user's management, but also by offering an outcome measure to evaluate the potential effects of such interventions. The META also supplies the clinicians with knowledge about environmental influences, which could guide them to support the user's management of ET, for example to choose ET with an easier design or to remove contextual hindrances for the use of a specific ET. A more inclusive design might ease the use of the ET (Lewis et al., 2008) and thereby decrease the need for adaptations. Nonetheless, more knowledge is needed about the environmental influence in terms of how and why design and contextual features are successful or not in the management of ET for older adults with or without cognitive impairment (Day et al., 2000; Topo, 2009).

The results of the final regression model demonstrated that $51.7 \%$ (adjusted $R^{2}=0.517$ ) of the ability to manage ET could be explained by the variations in the intrapersonal capacities, central tendency in environmental characteristics, and the diagnostic group. These results imply that ability to manage ET could not be predicted from diagnostic group measures alone, even though cognition has a significant impact on this ability (Malinowsky et al., 2010; Rosenberg et al., 2009). Unexpectedly, familiarity with the ET (how often and for how long the ET has been used) was not shown to be significant. Frequent use has previously been suggested as an important factor for successfully maintained ET use (Nygård, 2008) . One reason for this non-significance result might be the inclusion criteria for the ETs to be assessed in this study. In the assessments with the META, familiarity with the ET was seen as an important point of departure and therefore the ETs assessed were to be relevant, selfchosen, and currently used by the person. Almost $80 \%$ of the participants were assessed on 
their use of ETs that were used every day or weekly, and more than half of the participants were assessed on ETs they had used for at least three years. Accordingly, the inclusion criteria excluded ETs that were seldom used and thereby probably less familiar to the person.

Consequently, familiarity did not fall out as significant in the analyses, although it may be important in real life. On the other hand, it is possible that if a person is motivated to use a specific ET, the familiarity with the ET is of less importance. Motivation is known to be a factor that influences the performance of everyday activities (Kielhofner, 2008), and motivation has earlier been described to be important for continued use of ET in people with dementia (Nygård, 2008). In addition, perceived relevance of an ET has also been found to be related to competence in ET use for older adults (Rosenberg et al., 2009). The interrelationships between motivation and relevance on the competence in using ET among older adults should be studied further, especially in longitudinal research, in order to explore the process of how different aspects relate to the management of ET over time for older adults with and without cognitive impairment.

The results of this study must be viewed with caution due to some methodological limitations. First, the instrument used, the META, is a relatively recently developed instrument and has so far been used only to a limited extent in research (Malinowsky et al., 2010; Malinowsky et $a l ., 2011)$. It is also important to consider the validity of the independent variables. Six of the independent variables were based upon data from the META assessment, that is, they emanated from parts of the instrument where the psychometric properties have not been evaluated specifically. Second, the sample consists only of 110 individuals representing a limited selection of older adults with and without cognitive impairment. Potential participants with $\mathrm{AD}$ or MCI were not randomized but were identified based on specified inclusion criteria by the professionals at clinical investigation units in collaboration with members of 
the research group. The participants without known cognitive impairment were recruited from retirement organizations and similar networks. Hence, there is a risk that the sample in the study is not representative of other older adults with and without cognitive impairment. Third, in this study, intrapersonal capacities and environmental characteristics were assessed in relation to the specific performance when using ET rather than as general constructs. A potential relationship between these variables and the META person ability measure may therefore be expected, as the rater first scored the actual management ability and then, based upon all available information, judged the impact of intrapersonal capacities and environmental characteristics on the management of ET. On the other hand, the dependent variable, the META measure of person ability to manage ET, was a Rasch-generated measure in which rater severity, task challenge, and item difficulty had all been taken into consideration in producing a measure in the analysis phase. Thus a direct interpretation from the META raw scores on a more overall judgment of a person's ability to manage ET at the assessment session is not likely. In addition, the raters who completed the META evaluation and the evaluation of the personal and environmental conditions were not aware that the information would be used for this type of predictive analysis. In summary, although the META evaluation may have added qualitative information to the raters' judgments of personal and environmental conditions influencing the management of ET, the statistical association between the META measure and other independent variables are not expected to be systematically biased in this study.

In conclusion, this study suggests that the variability in intrapersonal capacities seems to be of more significance than the level of intrapersonal capacities in relation to the ability to manage ET for older adults with or without cognitive impairment. This implies that the assessment of ability to manage ET could also take into account performance variability within persons. 
Clinically, it may be important to make repeated assessments or a variation of assessments in order to capture variations in ability and receive more accurate and representative information when planning interventions. It was also demonstrated that the environmental characteristics seem to have a significant impact on the management of ET for older adults with or without cognitive impairment. This indicates that health professionals in interventions could facilitate their clients' management of ET by adaptations of the social and physical environment. 
Conflict of interest

None

Description of authors' roles

All authors formulated the research question and designed the study. C. Malinowsky, L. Nygård and A. Kottorp analyzed the data and wrote the paper. O. Almkvist contributed critical reflections and advice concerning analysis and interpretations of results.

\section{Acknowledgements}

First of all, the authors want to thank the participants who generously demonstrated their management of ET for us. We also want to thank the professionals at the investigation units who helped us to recruit participants. Particularly, the authors would like to thank Sofia Starkhammar, Monica Pantzar, Jenny Rasmussen Tjernlund, Susanne Andersson, Lizette Mårtensson, and Maria Carlsson for data collection and management. At last, we want to thank Jakob Bergström for support with statistical analyses. This research was mainly funded by the Health Care Sciences Postgraduate School. Financial support was also provided through Swedish Brainpower, Botkyrka municipality, the Swedish Council for Working Life and Social Research (FAS), and the regional agreement on medical training and clinical research (ALF) between the Stockholm County Council and Karolinska Institutet. 
References

American Psychiatric Association. (1995). Diagnostic and Statistical Manual of Mental Disorders. $4^{\text {th }}$ ed. (DSM-IV). Washington, DC: Author.

Artero, S. et al. (2008). Risk profiles for mild cognitive impairment and progression to dementia are gender specific. Journal of Neurology, Neurosurgery, and Psychiatry, 79, 979-984.

Bond, T.G. and Fox, C.M. (2007). Applying the Rasch Model: Fundamental Measurement in the Human Sciences. Mahwah, NJ: Lawrence Erlbaum.

Czaja, S.J., Charness, N., Fisk, A.D., Hertzog, C., Sankaran, N.N., Rogers, W.A. and Sharit, J. (2006). Factors predicting the use of technology: findings from the Center for Research and Education on Aging and Technology Enhancement (CREATE). Psychology and Aging, 21, 333-352.

Day, K., Carreon, D. and Stump, C. (2000). The therapeutic design of environments for people with dementia: A review of the empirical research. The Gerontologist, 40, 397-416.

Emiliani, P.L. (2006). Assistive Technology (AT) versus Mainstream Technology (MST): The research perspective. Technology and Disability, 18, 19-29.

Farias, S.T., Mungas, D., Reed, B.R., Harvey, D., Cahn-Weiner, D. and DeCarli, C. (2006). MCI is associated with deficits in everyday functioning. Alzheimer Disease \& Associated Disorders, 20, 217-223.

Folstein, M.F. and Folstein, S.E. (1975). McHugh P.R. "Mini Mental State Examination". A practical method for grading the cognitive state of patients for the clinician. Journal of Psychiatric Research, 12, 189-198.

Giovannetti, T., Bettcher, B.M., Libon, D., Brennan, L., Sestito, N. and Kessler, R.K. (2007). Environmental adaptations improve everyday action performance in Alzheimer's disease: Empirical support from performance-based assessment. Neuropsychology, 21, 448457. 
Holtzer, R., Verghese, J., Wang, C., Hall, C.B. and Lipton, R.B. (2008) Within-person across -neuropsychological test variability and incident dementia. JAMA, 300, 823-830.

Kielhofner, G. (2008). A Model of Human Occupation: Theory and Application (4 ${ }^{\text {th }}$ ed). Baltimore: Lippincott Williams \& Wilkins.

Lewis, T., Langdon, P.M. and Clarkson, P.J. (2008). Prior experience of domestic microwave cooker interfaces: A user study. In Langdon, P., Clarkson, J. \& Robinson, P. (Eds.), Designing Inclusive Futures. (pp.95-106). London: Springer.

Linacre, J.M. (1987-2006). FACETS: Many-faceted Rasch Measurement Computer Program (Version 3.61). Chicago: MESA.

Lövdén, M., Li, S-C, Shing, Y.L. and Lindenberger, U. (2007). Within-person trial-to-trial variability precedes and predicts cognitive decline in old and very old: Longitudinal data from the Berlin Aging Study. Neuropsychologia, 45, 2827-2838.

McKhann, G., Drachman, D., Folstein, M., Katzman, R., Price, D. and Stadlan, E.M. (1984). Clinical diagnosis of Alzheimer's disease: Report of NINCDS-ADRDA Work Group under the auspices of Department of Health and Human Task Force on Alzheimer's Disease. Neurology, 34, 939-944.

Malinowsky, C., Almkvist, O., Kottorp, A. and Nygård, L. (2010). Ability to manage everyday technology: A comparison of persons with dementia or mild cognitive impairment and older adults without cognitive impairment. Disability \& Rehabilitation: Assistive Technology, 5, 462-469.

Malinowsky, C., Nygård, L. and Kottorp, A. (2011) Psychometric evaluation of a new assessment of the ability to manage technology in everyday life for persons with or without cognitive impairment. Scandinavian Journal of Occupational Therapy, 18, 26-35.

Nygård, L. (2008) .The meaning of everyday technology as experienced by people with dementia who live alone. Dementia, 7, 481-502. 
Nygård, L. and Starkhammar, S. (2007). The use of everyday technology by people with dementia living alone: Mapping out the difficulties. Aging \& Mental Health, 11, 144-155.

Pereira, F.S., Yassuda, M.S., Oliveira, A.M. and Forlenza, O.V. (2008). Executive dysfunction correlates with impaired functional status in older adults with varying degrees of cognitive impairment. International Psychogeriatrics, 20, 1104-1115.

Perneczky, R. et al. (2006). Complex activities of daily living in mild cognitive impairment: conceptual and diagnostic issues. Age and Ageing, 35, 240-245.

Petersen, R.C. (2004). Mild cognitive impairment as a diagnostic entity. Journal of Internal Medicine, 256, 183-194.

Rosenberg, L., Kottorp, A., Winblad, B., Nygård, L. (2009). Perceived difficulty in everyday technology use among older adults with or without cognitive deficits. Scandinavian Journal of Occupational Therapy, 16, 216-226.

Royall, D.R., Lauterbach, E.C., Kaufer, D., Malloy, P., Coburn, K.L. and Black, K.J. (2007). The cognitive correlates of functional status: A review from the Committee on Research of the American Neuropsychiatric Association. The Journal of Neuropsychiatry and Clinical Neurosciences, 3, 249-265.

Selwyn, N., Gorard, S., Furlong, J. and Madden, L. (2003). Older adults' use of information and communication technology in everyday life. Ageing \& Society, 23, 561-582.

Slegers, K., van Boxtel, M.P.J. and Jolles, J. (2007). The effects of computer training and Internet usage on the use of everyday technology by older adults: A randomized controlled study. Educational Gerontology, 33, 91-110. 
Statistical Package for Social Sciences (2007). Version 16.0.1. Chicago: SPSS Inc.

Topo, P. (2009). Technology studies to meet the needs of people with dementia and their caregivers. A literature review. Journal of Applied Gerontology, 28, 5-37.

\section{Van Hooren, S.A.H., van Boxtel, M.P.J., Valentijn, S.A.M., Bosma, H., Ponds,}

R.W.H.M. and Jolles, J. (2005). Influence of cognitive functioning on functional status in an older population: 3- and 6-year follow-up of the Maastricht Aging Study. International Journal of Geriatric Psychiatry, 20, 883-888.

Winblad, B. et al. (2004). Mild cognitive impairment - beyond controversies, toward a consensus: report of the International Working Group on Mild Cognitive Impairment. J Intern Med, 256, 240-246. 
Table 1.

Characteristics of the participants $(n=110)$ in terms of age, gender, living conditions, years of education, occupation, MMSE score, and person ability measure in managing everyday technology.

\begin{tabular}{|c|c|c|c|c|}
\hline Group (n) & $\mathrm{OA}^{\mathrm{a}}(42)$ & $\operatorname{MCI}^{\mathbf{b}}(33)$ & Mild AD $^{c}(35)$ & $\begin{array}{l}\text { Comparison } \\
\text { between groups }\end{array}$ \\
\hline $\begin{array}{l}\text { Age, years mean } \\
\text { (SD) }\end{array}$ & 72.55 (9.65) & $70.82(8.55)$ & $75.54(9.21)$ & $\begin{array}{l}\text { Overall ANOVA NS }{ }^{\mathrm{d}} \\
\text { Bonferroni OA-MCI NS }\end{array}$ \\
\hline Range & $55-92$ & $57-87$ & $58-89$ & $\begin{array}{l}\text { OA-AD NS } \\
\text { MCI-AD NS }\end{array}$ \\
\hline Gender, n (\%) & $\begin{array}{l}\text { Men: } 17 \text { (40.5) } \\
\text { Women: } 25\end{array}$ & $\begin{array}{l}\text { Men: } 19(58) \\
\text { Women: } 14\end{array}$ & $\begin{array}{l}\text { Men: } 17(48.5) \\
\text { Women: } 18\end{array}$ & $\begin{array}{l}\text { Pearson } \mathrm{Chi}^{2} \\
\text { NS }\end{array}$ \\
\hline $\begin{array}{l}\text { Living } \\
\text { conditions, } \mathrm{n}(\%)\end{array}$ & $\begin{array}{l}\text { Cohabiting: } 23 \text { (55) } \\
\text { Single: } 19\end{array}$ & $\begin{array}{l}\text { Cohabiting: } 25 \text { (76) } \\
\text { Single: } 8\end{array}$ & $\begin{array}{l}\text { Cohabiting: } 18 \text { (51.5) } \\
\text { Single: } 17\end{array}$ & $\begin{array}{l}\text { Pearson } \mathrm{Chi}^{2} \\
\text { NS }\end{array}$ \\
\hline $\begin{array}{l}\text { Education, years } \\
\text { mean (SD) }\end{array}$ & $11.30(3.04)$ & $11.05(3.60)$ & $10.49(3.26)$ & $\begin{array}{l}\text { Overall ANOVA NS } \\
\text { Bonferroni OA-MCI NS }\end{array}$ \\
\hline Range & $6-18$ & $5-19.5$ & $5-17$ & $\begin{array}{l}\text { OA-AD NS } \\
\text { MCI-AD NS }\end{array}$ \\
\hline $\begin{array}{l}\text { Occupation, } \\
\text { (former or at } \\
\text { present), n (\%) }\end{array}$ & $\begin{array}{l}\text { Blue collar: } 19(45) \\
\text { White collar: } 23\end{array}$ & $\begin{array}{l}\text { Blue collar: } 14(42) \\
\text { White collar: } 19\end{array}$ & $\begin{array}{l}\text { Blue collar: } 19(54) \\
\text { White collar: } 16\end{array}$ & $\begin{array}{l}\text { Pearson } \mathrm{Chi}^{2} \\
\text { NS }\end{array}$ \\
\hline $\begin{array}{l}\text { MMSE }{ }^{\mathbf{e}} \text { score, } \\
\text { mean (SD) }\end{array}$ & $29.38(0.99)$ & $27.48(1.90)$ & $23.51(3.40)$ & $\begin{array}{l}\text { Overall ANOVA } p<.001 \\
\text { Bonferroni OA-MCI } p .001\end{array}$ \\
\hline Range & $27-30$ & $24-30$ & $17-29$ & $\begin{array}{l}\text { OA-AD } p<.001 \\
\text { MCI-AD } p<.001\end{array}$ \\
\hline $\begin{array}{l}\text { Person ability } \\
\text { measure in } \\
\text { logits, mean (SD) } \\
\text { Range }\end{array}$ & $2.14(0.87)$ & $1.44(0.84)$ & $0.70(0.65)$ & $\begin{array}{l}\text { Overall ANOVA } p<.001 \\
\text { Bonferroni OA-MCI } p .001 \\
\text { OA-AD } p<.001 \\
\text { MCI-AD } p .001\end{array}$ \\
\hline
\end{tabular}

Notes: ${ }^{\mathrm{a}} \mathrm{OA}=$ older adults without known cognitive impairment, ${ }^{\mathrm{b}} \mathrm{MCI}=$ mild cognitive

impairment; ${ }^{\mathrm{c}} \mathrm{AD}=\mathrm{Alzheimer}$ 's disease ${ }^{\mathrm{d}} \mathrm{NS}=$ non significant and ${ }^{\mathrm{e}} \mathrm{MMSE}=$ Mini Mental State Examination. 
Table 2.

Definitions of items in the Management of Everyday Technology Assessment (META). All items are scored on a three-category rating scale. Items A1-A10 assess performance of the management of everyday technology. Items B1-B3 and C1-C2 are assessed in relationship to how they affect the management of each technology assessed. Items D1-D2 concern familiarity of the technology assessed.

\begin{tabular}{ll}
\hline Performance skill items & A1. Follow instructions given by automatic \\
telephone services or answering machines \\
A2. Choose correct button or commando \\
A3. Identify services and function \\
A4. Perform actions in logical sequence \\
A5. Identify information and response adequately \\
A6. Manage series of numbers \\
A7. Use appropriate force, tempo, and precision \\
A8. Turn a button/knob in correct direction \\
A9. Coordinate different parts of a technology \\
A10. Identify and separate objects \\
B1. Capacity to manage stress \\
B2. Capacity to pay attention and focus \\
B3. Ability to recall necessary information \\
C1. Contextual influence \\
C2. Impact of the design \\
D1. How long the technology has been used \\
D2. How often the technology is used \\
Familiarity
\end{tabular}


Table 3. Description of classification of independent variables.

\begin{tabular}{|c|c|c|}
\hline Independent variable & Type of variable & Classification \\
\hline Diagnostic group & Categorical & $\begin{array}{l}0=\mathrm{OA}^{1} \\
1=\mathrm{MCI}^{2} \\
2=\mathrm{AD}^{3}\end{array}$ \\
\hline Gender & Categorical & Male or female \\
\hline Occupation & Categorical & $\begin{array}{l}\text { Blue or white collar } \\
\text { (former or at present) }\end{array}$ \\
\hline $\begin{array}{l}\text { Intrapersonal capacities - } \\
\text { central tendency }\end{array}$ & Categorical & Low or high median \\
\hline $\begin{array}{l}\text { Intrapersonal capacities - } \\
\text { variation }\end{array}$ & Categorical & $\begin{array}{l}\text { Four classes of variation } \\
\text { 1. No variation } \\
\text { 2. Low variation } \\
\text { 3. Average variation } \\
\text { 4. High variation } \\
\end{array}$ \\
\hline $\begin{array}{l}\text { Environmental characteristics } \\
\text { - central tendency }\end{array}$ & Categorical & Low or high median \\
\hline $\begin{array}{l}\text { Environmental characteristics } \\
\text { - variation }\end{array}$ & Categorical & $\begin{array}{l}\text { Four classes of variation } \\
\text { 1. No variation } \\
\text { 2. Low variation } \\
\text { 3. Average variation } \\
\text { 4. High variation } \\
\end{array}$ \\
\hline Familiarity - central tendency & Categorical & Low or high median \\
\hline Familiarity - variation & Categorical & $\begin{array}{l}\text { Four classes of variation } \\
\text { 1. No/very low variation } \\
\text { 2. Low variation } \\
\text { 3. Average variation } \\
\text { 4. High variation } \\
\end{array}$ \\
\hline
\end{tabular}

${ }^{1} \mathrm{OA}=$ older adults without known cognitive impairment. ${ }^{2} \mathrm{MCI}=$ persons with mild cognitive impairment. ${ }^{3} \mathrm{AD}=$ persons with mild Alzheimer's disease. 
Table 4. Examples of categorization of the intrapersonal capacities and environmental characteristics variables (based on items in the META) for assessments of management of everyday technologies for two participants.

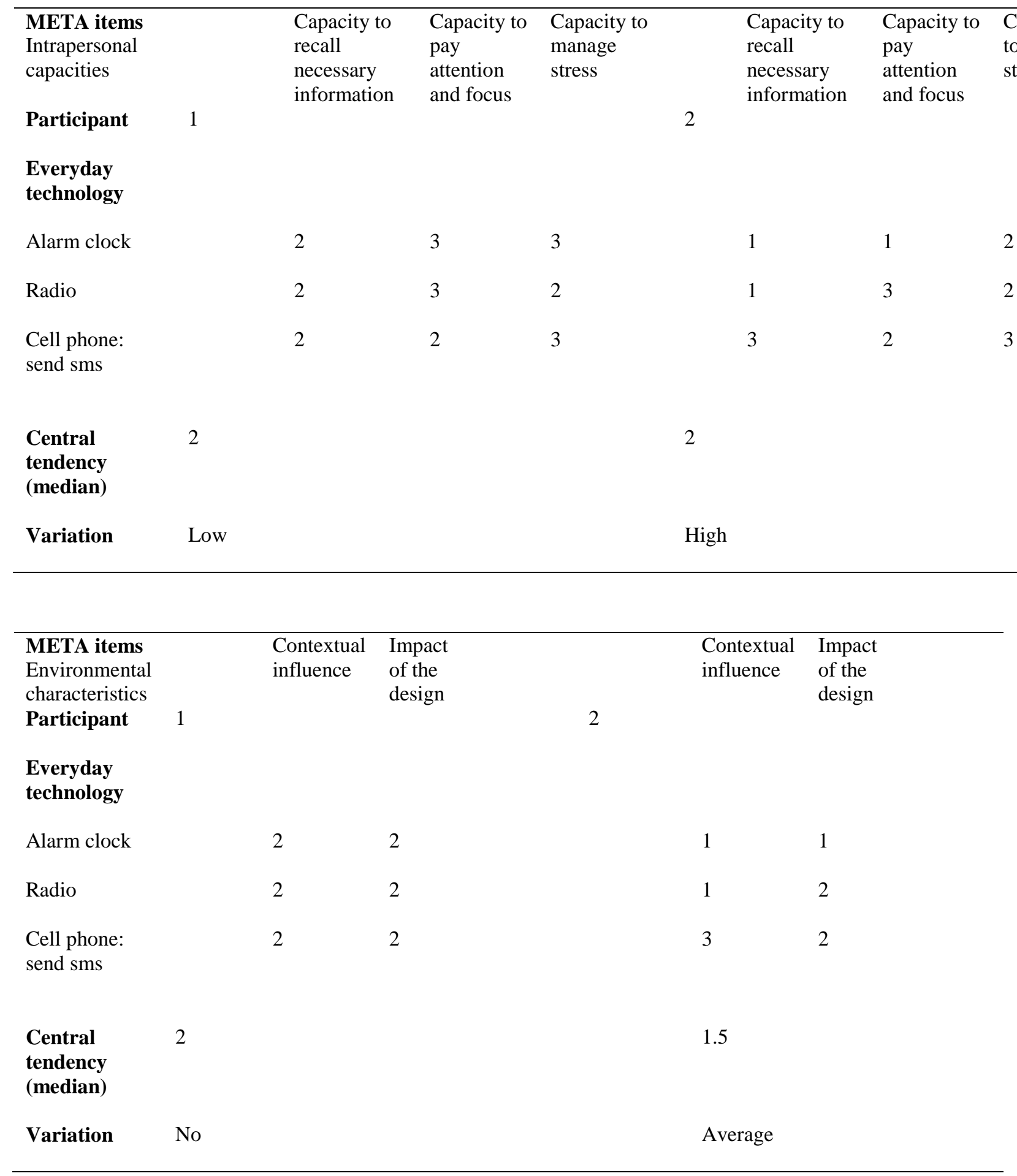


Table 5. Frequencies of different classes of the significant independent META variables, among the 110 older adults with and without cognitive impairment.

Class

Intrapersonal

capacities -

variation, $\mathrm{n}(\%)$

$\begin{array}{lll}1 & \text { No variation } & 25(22.5) \\ 2 & \text { Low variation } & 46(42) \\ 3 & \text { Average variation } & 24(22) \\ 4 & \text { High variation } & 15(13.5)\end{array}$

Environmental

characteristics -

central

tendency, n (\%) Low

$39(35.5)$

High $71(64.5)$ 
Table 6. Final model of ANOVA performed with person measure of ability to manage everyday technology as dependent variable $(n=110)$. Variables were included with a backward selection procedure with an inclusion criterion of $p<0.05$.

\begin{tabular}{|c|c|c|c|c|c|c|}
\hline \multirow[b]{2}{*}{ Effect } & \multirow[b]{2}{*}{ Comparison } & \multirow[b]{2}{*}{ Estimate } & \multicolumn{3}{|c|}{$95 \% \mathrm{CI}$} & \multirow[b]{2}{*}{$P$-value } \\
\hline & & & SE & Lower & Upper & \\
\hline \multirow[t]{3}{*}{$\begin{array}{l}\text { Diagnostic } \\
\text { group }^{1}\end{array}$} & $0^{\mathrm{a}}$ versus $1^{\mathrm{b}}$ & 0.429 & 0.181 & -0.011 & 0.869 & 0.058 \\
\hline & 0 versus $2^{c}$ & 0.840 & 0.195 & 0.364 & 1.316 & $<0.001$ \\
\hline & 1 versus 2 & 0.411 & 0.175 & -0.015 & 0.836 & 0.062 \\
\hline Gender $^{2}$ & $\begin{array}{l}\text { Men versus } \\
\text { women }\end{array}$ & 0.165 & 0.133 & -0.099 & 0.430 & 0.218 \\
\hline \multirow[t]{6}{*}{$\begin{array}{l}\text { Intrapersonal } \\
\text { capacities - } \\
\text { variation }^{3}\end{array}$} & 1 versus 2 & 0.436 & 0.192 & -0.080 & 0.951 & 0.151 \\
\hline & 1 versus 3 & 0.827 & 0.238 & 0.185 & 1.468 & 0.005 \\
\hline & 1 versus 4 & 0.917 & 0.272 & 0.185 & 1.650 & 0.006 \\
\hline & 2 versus 3 & 0.391 & 0.182 & -0.098 & 0.881 & 0.203 \\
\hline & 2 versus 4 & 0.482 & 0.217 & -0.103 & 1.067 & 0.173 \\
\hline & 3 versus 4 & 0.091 & 0.234 & -0.540 & 0.721 & 1.000 \\
\hline $\begin{array}{l}\text { Environmental } \\
\text { characteristics - } \\
\text { central } \\
\text { tendency }{ }^{4}\end{array}$ & $\begin{array}{l}\text { High versus } \\
\text { low }\end{array}$ & 0.566 & 0.150 & 0.267 & 0.864 & $<0.001$ \\
\hline
\end{tabular}

${ }^{1}$ Overall: $p<0.001 .{ }^{2}$ Overall: $p$ 0.218. ${ }^{3}$ Overall: $p$ 0.003. ${ }^{4}$ Overall: $p<0.001$.

${ }^{\mathrm{a}} 0=$ Older adults without cognitive impairment. ${ }^{\mathrm{b}} 1=$ Persons with MCI. ${ }^{\mathrm{c}} 2=$ =Persons with Alzheimer's disease. 